\title{
Phyllodes Tumours Will Only Get Bigger During Pandemic Restrictions
}

\author{
Sherif Monib ${ }^{1}$, Hany F. Habashy ${ }^{2}$ \\ 1. Breast Surgery, West Hertfordshire Hospitals NHS Trsut, St. Albans and Watford General Hospitals, London, GBR 2. \\ Surgical Oncology, Faculty of Medicine, Fayoum University, Fayoum, EGY
}

Corresponding author: Sherif Monib, sherif.monib@nhs.net

\begin{abstract}
Phyllodes tumours of the breast are rare fibroepithelial stromal tumours which are morphologically very different from epithelial breast cancer. Its diagnosis and management has always been challenging till the World Health Organization (WHO) divided it into two-three subtypes in 2003, only then it was found that incidence and management and follow-up of these three subtypes need to be completely different to reach the optimum outcome.
\end{abstract}

We are presenting a case of a 47-year-old female who presented relatively late (due to pandemic restrictions) with a large phyllodes tumour requiring mastectomy as well as adjuvant treatment.

Categories: General Surgery, Oncology

Keywords: phyllodes tumour, who classification, mastectomy, adjuvant treatment

\section{Introduction}

Phyllodes tumour was first described by Johannes Müller in 1838, as cystosarcoma phyllodes [1], which was later found to be not a very accurate description, as phyllodes tumours are rarely cystic, and the majority of them tend to be more benign than sarcomatous. More than 60 synonyms have been reported for the same condition [2], till the World Health Organisation (WHO) regarded phyllodes tumour as the most appropriate nomenclature [3].

Review began 12/07/2020 Review ended 12/20/2020 Published 12/26/2020

() Copyright 2020

Monib et al. This is an open access article distributed under the terms of the Creative Commons Attribution License CC-BY 4.0., which permits unrestricted use, distribution, and reproduction in any medium, provided the original author and source are credited.
Phyllodes tumours are fibroepithelial tumours that comprise $2-3 \%$ of all fibroepithelial breast tumours and $0.3-1.0 \%$ of all breast tumours [4,5]. Phyllodes tumours predominantly occur in middle-aged women with average age at presentation, between 40 to 50 years [6], and the average annual incidence of malignant phyllodes tumours is 2.1 per 1 million women [7].

The wide-ranging clinical presentation and pathological features of phyllodes tumours contribute to preoperative diagnostic difficulties. Triple assessment in the form of clinical examination, mammography and/or breast ultrasound scan followed by guided core biopsy is crucial for early diagnosis, classification as well as surgical planning [8].

\section{Case Presentation}

We are presenting a case of a 47-year-old female who presented to our outpatient department with left breast large mass which has been steadily growing over the last year, but the patient was a bit apprehensive about seeking medical advice due to the current pandemic restrictions.

Her past medical history, and family history, were irrelevant. Breast examination revealed a left breast P4 $20 \mathrm{~mm}$ mass occupying the lateral half of the left breast (Figure 1), with no other palpable ipsilateral or contralateral other breast lumps, axillary or supraclavicular lymph nodes. 


\section{Cureus}

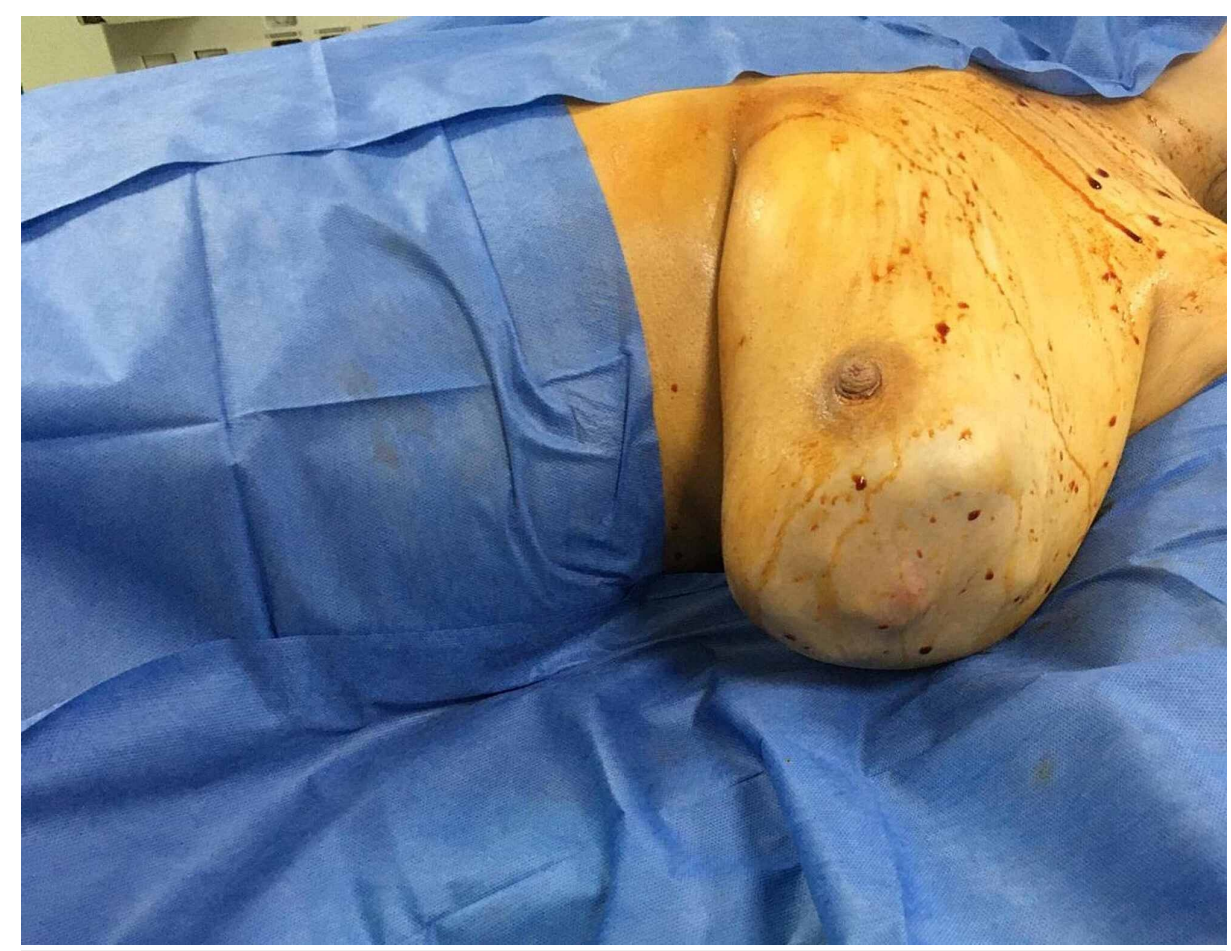

FIGURE 1: Intraoperative picture showing the large phyllodes tumour occupying the lateral aspect of the breast even seen by inspection.

Mammography showed a (Breast Imaging Reporting and Database System) BI-RADS 5 18-mm mass (Figures $2,3)$, ultrasound scan-guided core biopsy revealed high-grade malignant phyllodes tumour, and axillary lymph nodes fine needle aspiration cytology (FNAC) showed metastatic disease. 


\section{Cureus}

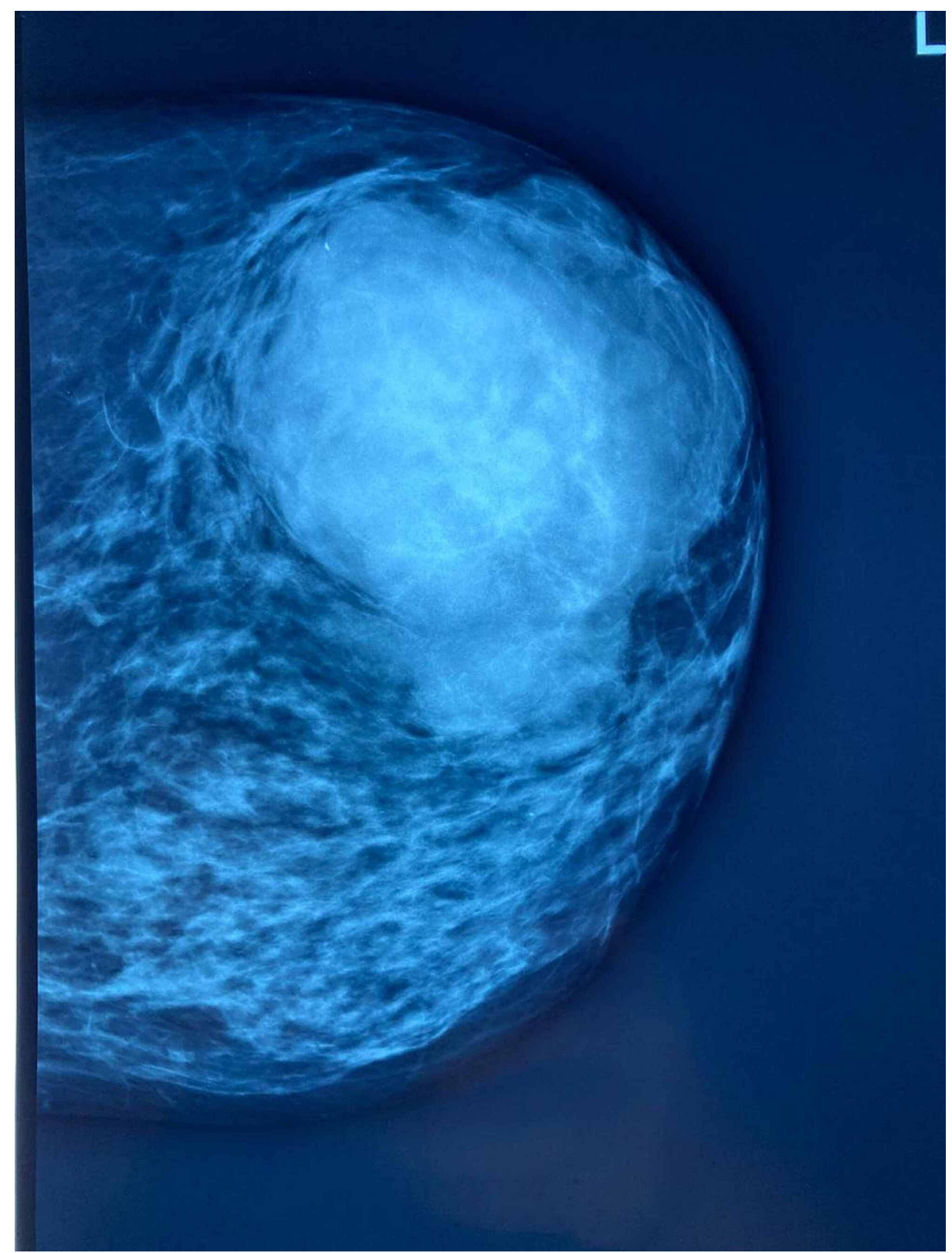

FIGURE 2: Left craniocaudal mammogram showing the large phyllodes tumour occupying the lateral aspect of the breast. 


\section{Cureus}



\section{FIGURE 3: Left mediolateral mammogram showing the large phyllodes tumour occupying the lateral aspect of the breast.}

Taking into consideration adequate margins required for complete resection of malignant phyllodes tumours, a mastectomy was carried out. The patient had an uneventful recovery, and she was discharged on the following day, seen in the clinic one week postoperatively, with no postoperative complications noted, and final histology confirmed clear resection margins. Based on the size of the tumour and the likelihood of recurrence, adjuvant chemotherapy, as well as chest wall radiotherapy, was advised. We also arranged for six-monthly chest $\mathrm{X}$-ray and clinical examination, as well as annual right-sided mammogram.

\section{Discussion}

Phyllodes tumours are rare breast tumours which are histologically different from breast carcinoma as they originate from the stromal tissue rather than ductal or lobular tissue [9]. While the majority of these tumours develop de novo, there have been reports of progression of fibroadenoma to phyllodes tumour [10].

Phyllodes tumours can pose a significant burden not only for patients but also for health facilities, as in many cases, diagnosis and management is not as straight forward as expected, with some tumours found to be malignant after excision requiring further re-excisions, adjuvant treatment and lengthy costly follow-up.

Based on histologic features, including stromal cellularity, nuclear atypia, mitotic activity, tumour margin 
appearance, and stromal overgrowth, the WHO international histological classification group divided phyllodes tumours into three subtypes: benign tumours which represent $58 \%$, borderline tumours which represent $12 \%$ and malignant tumours which represent $30 \%$ of all phyllodes tumours $[4,11]$.

With surgery, the mainstay of treatment for phyllodes tumours surgical margins $\geqslant 10 \mathrm{~mm}$ is always recommended [12]; unfortunately, as our patient presented late with a sizable tumour progressively increasing in size. Taking into consideration breast to tumour ratio as well as adequate margins required, we thought that a mastectomy would be a safer option rather than wide local excision. Axillary lymph node clearance is not necessary in all cases and is only indicated in the evidence of lymph node metastasis [13], which was also the case with our patient.

While local recurrence rate is $20 \%$, distant metastases to lungs, bones, brain, and liver is estimated to be around 3.5\%; therefore, chemotherapy (ifosfamide, etoposide, doxorubicin, or cisplatin), and radiotherapy should be considered in case of high recurrence or metastatic risk [14,15]. Based on these findings, we have recommended adjuvant chemotherapy and chest wall radiotherapy to our patient.

Since the five-year disease-free survival rate in patients with benign phyllodes tumours is around $96.9 \%$, borderline tumours $83.3 \%$, and malignant tumours $71.7 \%$ [16], so every effort should be made to diagnose and treat these patients as early as possible. Early diagnosis of smaller-sized tumours will not only facilitate conservative breast surgery and decrease the need for mastectomy, but also improve prognosis and patient satisfaction.

\section{Conclusions}

In our case, delay in diagnosis and treatment due to the pandemic restriction led to the need for a mastectomy rather than conservative breast surgery. We believe that diagnosis of phyllodes tumours will facilitate a more localised approach of treatment and decrease the need for more radical treatments.

Since phyllodes tumours are morphologically different from epithelial breast cancers, we recommend a multicentric study including large numbers of the three subtypes of phyllodes tumour to be able to come up with solid guidelines for indications and extent of breast and axillary surgery as well as adjuvant treatment and follow up of each subtype to achieve the best outcomes.

\section{Additional Information \\ Disclosures}

Human subjects: Consent was obtained by all participants in this study. No ethical approval was required issued approval . Conflicts of interest: In compliance with the ICMJE uniform disclosure form, all authors declare the following: Payment/services info: All authors have declared that no financial support was received from any organization for the submitted work. Financial relationships: All authors have declared that they have no financial relationships at present or within the previous three years with any organizations that might have an interest in the submitted work. Other relationships: All authors have declared that there are no other relationships or activities that could appear to have influenced the submitted work.

\section{References}

1. Müller J: Uber den feineren Ban und Die Formen der Krankaften Geschwulste . 1838, 1:54-57.

2. Fiks A: Cystosarcoma phyllodes of the mammary gland--Müller's tumor: for the 180th birthday of Johannes Müller. Virchows Arch A. 1981, 392:1-6. 10.1007/BF00430543

3. World Health Organization: Histological Typing of Breast Tumors . World Health Organization, Geneva, Switzerland; 1982.

4. Tavassoli FA: Pathology and Genetics of Tumours of the Breast and Female Genital Organs. World Health Organization Classification of Tumours. International Agency for Research on Cancer (IARC) Press, Lyon; 2003.

5. Guerrero MA, Ballard BR, Grau AM: Malignant phyllodes tumor of the breast: review of the literature and case report of stromal overgrowth. Surg Oncol. 2003, 12:27-37. 10.1016/s0960-7404(03)00005-7

6. Jing P, Wei B, Yang X: Phyllodes tumor of the breast with nipple discharge: a case report . Medicine. 2018, 97:13767. 10.1097/MD.0000000000013767

7. Bernstein L, Deapen D, Ross RK: The descriptive epidemiology of malignant cystosarcoma phyllodes tumors of the breast. Cancer. 1993, 71:3020-3024. 10.1002/1097-0142(19930515)71:10<3020::aidcncr2820711022>3.0.c0;2-g

8. Zhou ZR, Wang CC, Yang ZZ, Yu XL, Guo XM: Phyllodes tumors of the breast: diagnosis, treatment and prognostic factors related to recurrence. J Thorac Dis. 2016, 8:3361-3368. 10.21037/jtd.2016.11.03

9. Mituś JW, Blecharz P, Jakubowicz J, Reinfuss M, Walasek T, Wysocki W: Phyllodes tumors of the breast. The treatment results for 340 patients from a single cancer centre. Breast. 2019, 43:85-90. 10.1016/i.breast.2018.11.009

10. Faridi SH, Siddiqui B, Ahmad SS, Aslam M: Progression of fibroadenoma to malignant phyllodes tumour in a 14-year female. J Coll Physicians Surg Pak. 2018, 28:69-71. 10.29271/jcpsp.2018.01.69

11. Chaney AW, Pollack A, McNeese MD, Zagars GK, Pisters PWT, Pollock RE, Hunt KK: Primary treatment of 


\section{Cureus}

cystosarcoma phyllodes of the breast. Cancer. 2000, 89:1502-1511. 10.1002/1097-

0142(20001001)89:7<1502::aid-cncr13>3.0.c0;2-p

12. Macdonald OK, Lee CM, Tward JD, Chappel CD, Gaffney DK: Malignant phyllodes tumor of the female breast: association of primary therapy with cause-specific survival from the Surveillance, Epidemiology, and End Results (SEER) program. Cancer. 2006, 107:2127-2133. 10.1002/cncr.22228

13. Khosravi-Shahi P: Management of non metastatic phyllodes tumors of the breast: review of the literature Surg Oncol. 2011, 20:143-148. 10.1016/j.suronc.2011.04.007

14. Belkacémi Y, Bousquet G, Marsiglia H, et al.: Phyllodes tumor of the breast. Int J Radiat Oncol Biol Phys. 2008, 70:492-500. 10.1016/j.ijrobp.2007.06.059

15. Shafi AA, AlHarthi B, Riaz MM, AlBagir A: Giant phyllodes tumour with axillary \& interpectoral lymph node metastasis; a rare presentation. Int J Surg Case Rep. 2020, 66:350-355. 10.1016/j.ijscr.2019.12.026

16. Mituś JW, Blecharz P, Walasek T, Reinfuss M, Jakubowicz J, Kulpa J: Treatment of patients with distant metastases from phyllodes tumor of the breast. World J Surg. 2016, 40:323-328. 10.1007/s00268-015-3262-7 